\title{
造城建家一一香港城市规划回顾与展望
}

\section{Building a Town for Home: Review and Perspective of Urban Planning in Hong Kong}

凌嘉勤

Ling K.K. Jiaqin

摘要: 回顾香港开埠至今 170 多年, 不算长却 也不能说短的城市发展历程, 期间挑战重重, 难关处处。西方城市规划的理论及实践被引进 香港, 逐渐构建了与香港本土情况相互适应的 规划理念、策略及体制。这是一个值得我们深 入探究的课题。

Abstract: Reviewing the history of Hong Kong's opening up to be an international free port for over 170 years, its urban development process is neither long nor short while it still met a large number of challenges and difficulties. The urban planning theories and practices from Western countries have been introduced into Hong Kong, and have developed the planning concepts, strategies and systems in accordance with Hong Kong's local conditions. This worths a long-lasting research.

关键词: 城市发展; 规划; 高密度; 香港 Keywords: Urban Development; Planning; High Density; Hong Kong
“相其阴阳之和, 尝其水泉之味, 审其土地之宜, 观其草木之饶, 然后营邑立城, 制里割宅, 通田作之道, 正阡陌之界, 先为筑室。”

《汉书・泉错传》

\section{1 香港城市规划范式}

相对于西方土地资源较丰富的情况而言, 香港总要面对人口多而可开发土地 少的挑战。自 20 世纪 60 年代至 20 世纪末, 平均每 10 年增加 100 万人口 ; 进人 21 世纪则降低至每 10 年增加 50 万人口。2014-2044 年, 预计香港的人口仍会 增加 $13.5 \%$ (约 98 万人), 家庭住户数会因为同时受平均每户人数下降而增加得 更快, 达 $20.4 \%$ (约 50 万户)。现今香港已开发的土地约只占全港土地总面积的 $24 \%$, 将来加上在策略规划上的潜在发展地区及正在进行规划研究的土地, 已开 发加上将开发的土地仍只占全港的 $28 \%$, 其余都是乡郊山岭土地。因此, 高密度 及高层开发正是因应本地情况而塑造出的切合香港的发展模式和城市型态, 以满 足香港的经济及民生发展的需要。20 世纪六七十年代, 一些西方城市规划界人士 对高密度城市发展模式还存有疑问, 甚至出现将高层高密度小区整个炸掉推倒的 极端案例 ${ }^{1}$ 。然而, 今天香港经历了不同年代的规划及实践, 高密度紧凑型的城 市发展模式能够充分考虑环境、保育等因素，配以合理的空间布局及恰当的公共 设施和休憩用地，加以高效的市政服务和城市管理，成功为市民构建了便捷而又 充满活力的城市环境, 成为现代城市发展模式的一个典范。

20 世纪 90 年代, 外国城市规划界开始反思西方城市以汽车为主导, 推动 “郊 区化” (suburbanization) 的城市扩展模式, 并提倡 “公交导向发展” (TOD: Transitoriented Development) (2)。事实上, 香港早于 20 世纪 80 年代制定的《全港发展策 略》(Territorial Development Strategy) 就已明确制订了以公交, 特别是以铁路为骨干, 协调土地利用及空间布局的战略 ${ }^{[1]}$ 。现如今, 香港每天出行交通量约 $90 \%$ 都是利 用公交, 其中约 $40 \%$ 是依靠铁路。全港约 $75 \%$ 的商业及办公室楼面面积, 以及约

作者：凌嘉勤, 香港规划署前署长 (2012-2016), 香港大学名誉教授。kkling@hku.hk

(1) 20 世纪 50 年代, 在美国密苏里州圣路易斯 (St. Louis) 城内所兴建名为Pruitt-Igoe 的高密度发展, 于 1970 年代被炸毁。

(2) 20 世纪 90 年代初, 新城市主义的倡导者之一卡尔索普 (Peter Calthorpe) 在其著作《跨世纪都会蓝图 : 生态·社区・愿景》(The Next American Metropolis: Ecology, Community, and the American Dream) 中积极推崇“公交为导向的发展模式”发展模式, 广受当时学界及业界认同。 
$40 \%$ 住宅都在铁路车站 $500 \mathrm{~m}$ 可步行的距离内 ${ }^{[1]}$ 。

以公交为导向的高密度紧凑型城市发展模式, 现已普遍 成为全球规划界认同的可持续的城市发展模式。香港在这方 面是先行者, 更是坚定的实践者, 为世界城市化进程提供了 重要的范式和参考。

\section{2 新世纪之初的演进}

自 1997 年回归到踏人 21 世纪, 香港城市规划的演进也许 可以归纳为三方面的蜕变：(1) 制度更公开及透明 ; (2) 工作 范式更多元与包容; (3) 多中心、多轴线空间发展模式的形 成及强化。

《2004 年城市规划（修订）条例》的实施, 使城市规划 制度在规划信息的提供、公众发表意见的渠道、城市规划委 员会对规划申请的审议、法定图则的制定和公众申述的考虑 等方面都有更公开和透明的安排。这些制度上的改革, 提供 了一个更为开放及包容的平台, 促进了各利益相关方在城市 规划议题上更活跃的互动, 使各项规划建议受到了更广泛和 密切的民间关注和监察。

“发展主导”这个曾协助战后香港有效应对众多挑战的 规划范式, 虽然仍是规划工作的主流, 但其在操作上必须更 为多元与包容, 才能应对现今复杂多变的挑战与诉求。城市 设计、都市更新、地方营造、智能城市、环境保护、生态和 文化保育、可持续发展、生物多样性、气候变化, 以及人口 老龄化等考虑因素, 在规划思维与工作中愈加重要。
经过战后历次的策略规划发展和新市镇发展, 我们在 维多利亚港两岸的传统发展区之外成功建设了 9 个新市镇, 包括荃湾、沙田、屯门、大埔、元朗、粉岭 /上水、将军澳、 天水围和东涌。这些新市镇与都会区皆以铁路为骨干的高 运量交通走廊连接, 形成并强化了多中心、多轴线的空间 格局。如今全港约有一半人口住在这些新市镇。然而, 在 经济活动及就业方面, 我们未能形成与之相对称的空间分布, 因为超过七成的就业职位仍在都会区, 导致了高流量、长距 离的单向通勤流动, 各条主干道在繁忙时段会出现严重的堵 塞。就业人群在交通上消耗大量时间, 亦增加了车辆的碳排 放量（图 1)。以上分析笔者已在《传城立新》 ${ }^{[1]}$ 一书的序言 有所论述。

\section{3 新发展周期的主要规划倡议}

目前香港的新市镇发展已进人新周期, 我们现在以智能、 环保及具抗御力的概念规划及发展新一波的新市镇, 为市民 创造更宜居的城市环境。这些新发展区包括古洞北、粉岭北、 东涌东及西、洪水桥及元朗南, 它们正处于不同的规划级发 展阶段, 将成为新一批宜居的智能新市镇。在规划新一波的 新市镇时我们提出四大倡议 ${ }^{[3]}$ 。

(1) 平衡就业及居住的需要。以往新市镇侧重发展房屋 以应付人口增长, 令新市镇的居民需要长途跋涉往返市区工 作。为避免再次出现这种情况, 政府将来会在新市镇预留充 裕的土地发展经济, 创造新职位, 逐步改善居住人口与就业

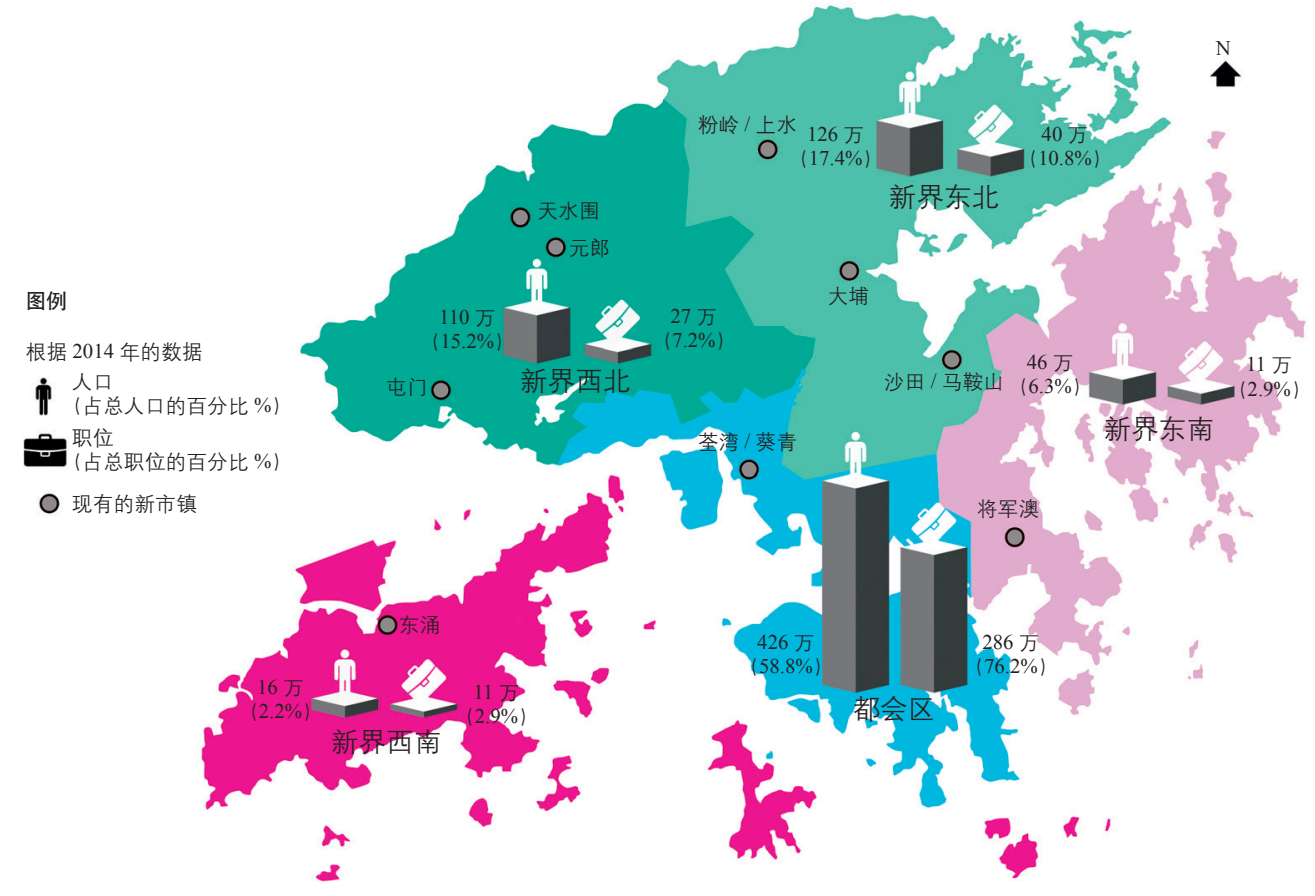

图 1 香港人口与职位地点的空间分布 (2014)

资料来源 : 参考文献 [2] 
职位空间分布不平衡的状态。例如日后洪水桥及元朗南等新 发展区将预留土地发展多种用途, 包括办公楼、零售、酒店、 货仓、工场以及物流、创新科技及检测和认证等。连同其他 区内新市镇包括屯门、元朗、天水围, 新界西北区内总共将 提供约 36 万个就业机会, 约为总人口的三成, 这样可望促 进本区就业和减轻跨区交通的压力。

（2）尽可能实现 “城、乡、自然共融”。例如在新界东 北的古洞北新发展区内, 约有 $37 \mathrm{hm}^{2}$ 具高生态价值的塱原 湿地被保留作自然生态公园之用, 以协助推广自然生态教育 (图 2); 同时位于其南、北的大片农地则被保留作农业用途。 塱原湿地与两片农地将是新发展区的“绿肺”, 可以保留该 区现有的乡野特色, 缔造多元化的城市景观和优质生活环境。 在洪水桥新发展区的土地利用规划方案中, 我们也对大片传 统乡村聚落进行保育, 在其周围以市镇公园、经活化的河道 和市容美化地带与高密度发展区适度分隔, 但在城市功能及 市政服务的系统配置上, 又有恰当的融合。

（3）营造绿色宜居环境。我们会在新发展区内致力于创 造绿色低碳的生活环境。新发展区采用 TOD 模式, 以铁路 为交通骨干, 未来人口的 $80 \%$ 将布置在距离铁路车站及公 交交汇处的 $500 \mathrm{~m}$ 范围内, 居民日常生活因而可以多步行、 多骑行。通过兴建集零售购物、公园、行人网络系统、通风 走廊及视觉走廊等五合一用途的步行街等措施, 可提升居民 步行体验, 吸引更多人选择步行。此外在新发展区亦会推广 节能建筑, 通过更完善的污水及洪水处理系统等, 促进污水 循环使用, 令新发展区更为绿色宜居。
（4）通过地方营造概念, 在新发展区的中心点提供优质 公共空间, 以缔造归属感及加强城市活力。在洪水桥新发展 区邻近市中心洪水桥站将建设区域广场, 成为区域枢纽的重 要通风及休闲空间, 并辅以区域文娱中心、政府办公楼、新 的小区中心等 (图 3)。在古洞北新发展区, 市中心有合理 规划的行人大道, 阶梯式的平台和朝向街道的商铺, 丰富了 城市的活力; 同时, 南北向和东西向的绿化走廊不但可作为 通风廊道和视觉走廊, 也在市中心提供了公共空间和行人区 (图 4)。我们期望这些规划概念将为新发展区带来充满活 力和生气的市中心, 提升居民的生活体验与归属感。

这些新市镇概念将提供更均衡和设备更齐全的社区, 使 市民的生活质量大大提升。长远而言, 每个新市镇均能发展 自己的特色, 力争成为新市镇发展的范例。总的来说, 由于 市民对于改善居住环境和生活空间有所期望，所以一般新发 展区的规划都会有较高比例的政府、机构或社区用地、休憩 用地, 以至能够尽量保留原有乡村或农地、绿地。以古洞北/ 粉岭北新发展区为例, 房屋用地占 $16 \%$, 政府、机构或社区 用地加上休憩用地占 $20 \%$, 道路占 $12 \%$; 另一方面, 乡村、 农业、绿化地带及自然保育区等则占 $40 \%$, 当中包括 $37 \mathrm{hm}^{2}$ 的暨原自然生态公园及 $58 \mathrm{hm}^{2}$ 农地, 以平衡发展保育 ${ }^{[6]}$ 。与 此同时, 我们亦需要提供足够经济用地以满足经济活动和就 业需要。

\section{4 跨越 2030 年的规划远景与策略}

刚在 2016 年 10 月公布的《香港 $2030+$ ：跨越 2030 年

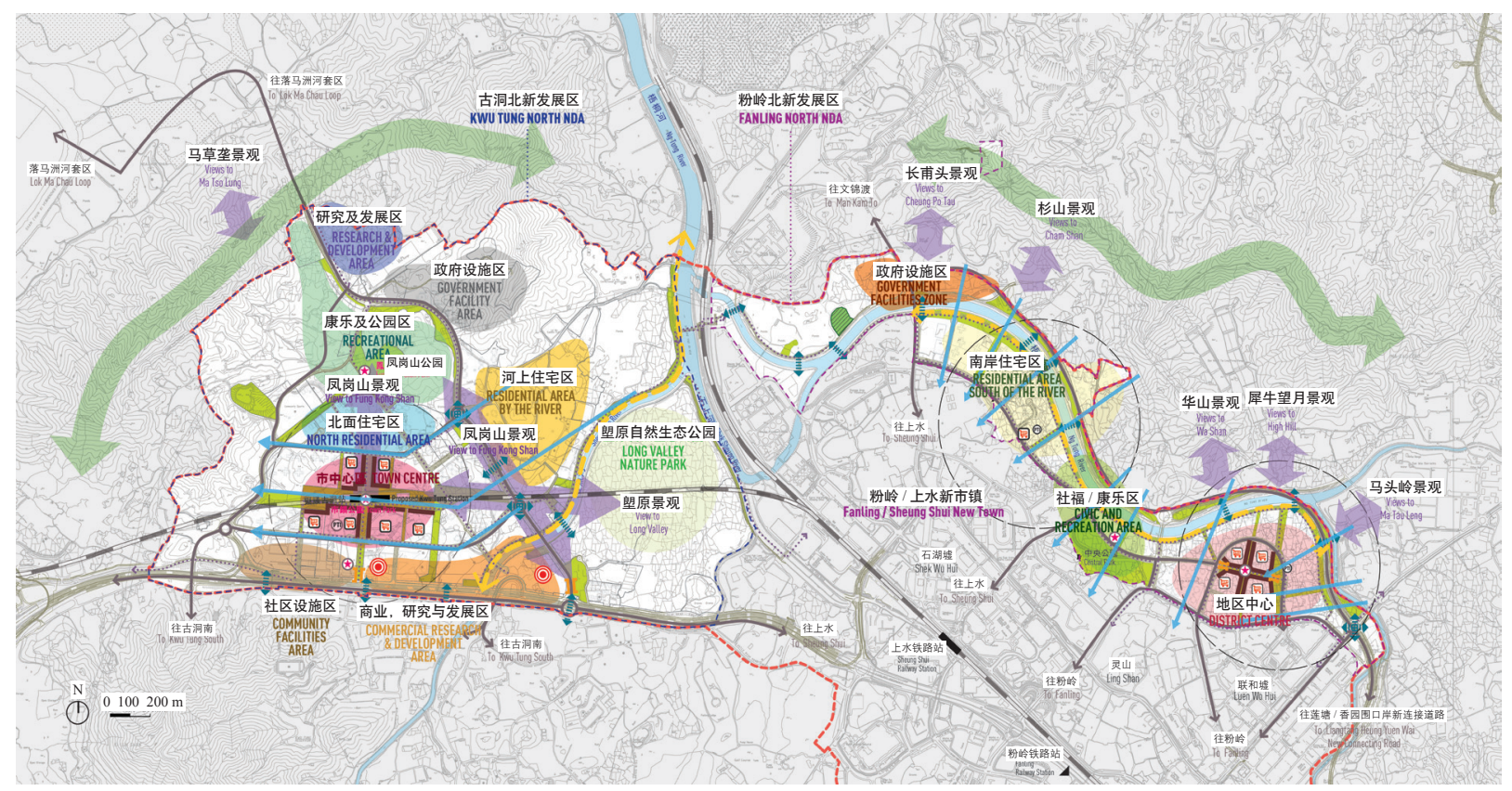

图 2 古洞北新发展区一一拟议土地用途及建议保留作自然生态公园的塱原湿地 资料来源 : 参考文献 [4] 
的规划远景与策略》（以下称《香港 2030+》) 是我们在全港 层面上的最新规划构想一一致力于智能、环保及具抗御力的 城市策略, 推动香港成为一个宜居、有竞争力和可持续发展 的 “亚洲国际都会”。我们检视了相应的主要规划方向和策 略, 并建议了三个元素——规划宜居的高密度城市、迎接新 的经济挑战与机遇、创造容量以致可持续发展，并建立了一 个概念性空间框架 ${ }^{[7]}$ 。

（1）《香港 2030+》首个元素是 “规划宜居的高密度城 市”。集约而高密度的城市形态令香港便捷、高效和活力充沛, 但同时亦衍生出不少问题, 例如狭小的居住和工作空间、交 通堵塞和热岛效应等。为使高密度集约式城市更加宜居, 我 们建议采用双管齐下的策略：一方面改造密集发展的市区， 另一方面优化新发展区。通过优良的城市设计、合适的发展 密度和混合利用, 改善行人环境质量, 提升都市的流动性和 可达性, 重塑公共空间并改善公共设施等, 我们希望为市民 提供更好的居住及生活环境，提升市民整体的生活质量。与 此同时, 我们亦建议更新日渐老化的城市结构, 使旧区成为 富活力、安全又舒适的地方。

此外, 我们亦认为需要提供更多土地和空间为政府、机 构及社区所用，以容纳政府及社区设施及服务，并增加休息 用地的供应。这样既可以满足公众对增加小区设施及休憩用 地的期望，更能提供空间以协助落实一些改善社区设施的措 施。具体来说, 我们注意到上一代的新市镇, 例如沙田, 区 内可提供作为政府、机构及社区用途的用地约为每人 $2.2 \mathrm{~m}^{2}$; 而在新一代的新发展区, 如古洞北, 区内可提供的相应面积 则达每人约 $3.5 \mathrm{~m}^{2}$ 。因此, 我们建议采用每人 $3.5 \mathrm{~m}^{2}$ 这个 较高面积的标准, 为《香港 $2030+$ 》的政府、机构及社区用 地进行规划。同样, 留意到《香港规划标准与准则》目前就 休憩用地的整体规定是每人 $2 \mathrm{~m}^{2}$, 我们建议以每人不少于 $2.5 \mathrm{~m}^{2}$ 为标准, 为《香港 $2030+$ 》的休喤用地进行规划。

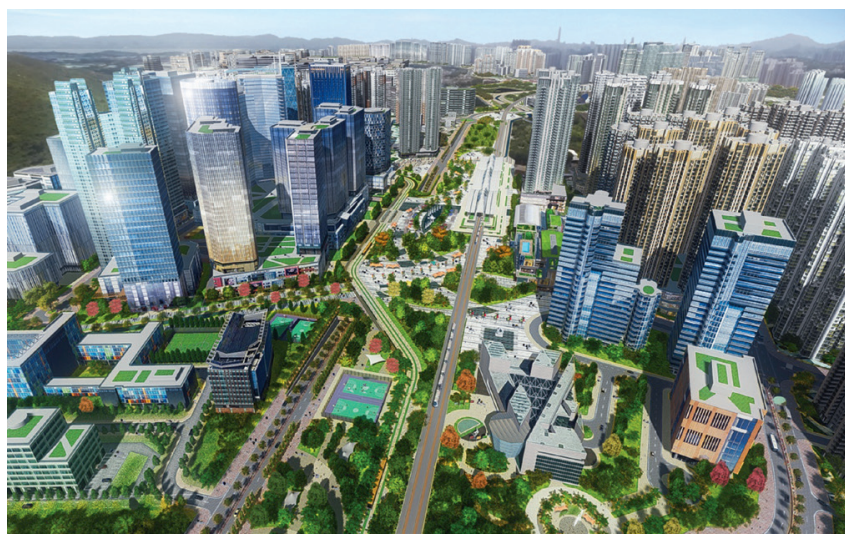

图 3 洪水桥新发展区一一拟议洪水桥站及邻近的区域广场 资料来源 : 参考文献 [5]
（2）《香港 2030+》第二个元素是 “迎接新的经济挑战 与机遇”。踏人 21 世纪, 中国内地经济发展迅速, 加上大力 推行的自由贸易区及 “一带一路” 等政策措施, 将对全球经 济格局带来重大改变, 再加上内地与香港经济日益紧密, 香 港将面临巨大的经济机遇。为应对这一趋势, 我们必须继续 力争上游, 迎合新的经济发展模式。

为确保香港经济可持续发展, 我们必须: 提供足够土地 和空间, 以应付当前的短缺乃至未来各类经济用途的需求; 促进经济领域多元化, 并创造技能层面广泛的优质职位; 促 进创新科技与合作；提供足够和合适的人力资源；适时提供 足够的基建配套设施。

《香港 2030+》已就市场主导的经济用途（包括甲级写 字楼、一般商贸和工业）对未来土地和空间的需求做出推算。 政府亦已就各项政策主导的经济用途（包括科学园及工业邨 等) 的长远土地和空间需求做出估算, 力求能提供足够合适 的土地, 支持香港经济的长远发展。

（3）《香港 2030+》第三个元素是 “创造容量以达致可 持续发展”。为了实现香港的可持续发展, 我们需要一种优 化的策略性规划模式, 利用智能、环保及具抗御力的城市策 略, 全面地创造发展容量并提升环境容量。在创造发展容量 方面, 这一经优化的策略性规划模式不单旨在应付按人口增 长和经济发展趋势推算出来的土地需求, 亦从长远的角度预 先积极创造足够土地及空间, 包括潜在需求和现时未能预见 的情况, 以应付不时之需。这有别于以往以需求主导的规划 模式, 旨在避免香港在过去 10 年土地供应一直落后于需求 的情况再度出现。

在提升环境容量方面, 这一经优化的策略性规划模式旨 在创造、提升及再生环境容量, 并把环境保育及生物多样性 纳人考虑过程, 以做规划及决定。其中除了避免在环境和生 态敏感地区进行大力开发外, 亦通过主动的保育方案、适当

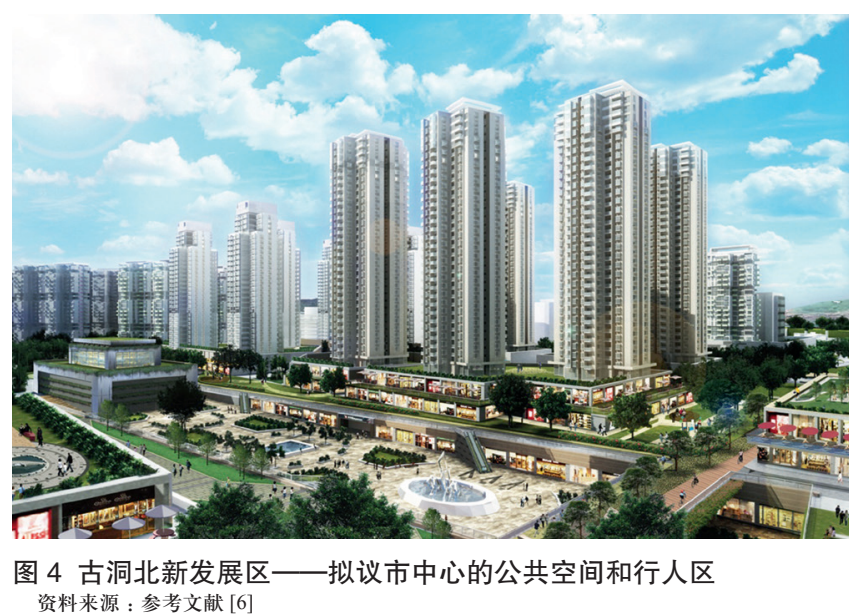


的管理、恰当的规划和设计, 以及减少消耗资源和污染措施, 创造环境容量并推动其再生。

在土地供求方面, 粗略估算香港目前至 2040 年就房屋、 经济用途、小区和运输设施及休憩用地的新增土地总需求将 不少于 $4800 \mathrm{hm}^{2}$, 扣除已落实及已规划的工程项目所提供 的约 $3600 \mathrm{hm}^{2}$ 的土地, 我们尚欠逾 $1200 \mathrm{hm}^{2}$ 土地。在运输 基建方面, 我们注意到限制私家车辆的增长和使用情况对香 港的可持续发展至为重要。截至 2015 年年底, 私家车辆的 数目约为 57 万辆, 若目前的趋势持续, 估计在 2041 年, 拥 有私家车辆的比例会进一步增至每千住户约 420 辆, 几乎是 目前比例的两倍。这个增长幅度不可持续, 否则私家车辆的 增长和使用会对整体运输系统造成巨大压力。

（4）《香港 2030+》亦提出了一个明确的策略性概念空 间框架, 把上述三大元素转化到空间规划, 为土地及基建发 展提供指引, 让香港得以可持续发展。建议的空间框架主要 包含三个部分：

-一个都会商业核心圈, 包括传统商业核心区、九龙东 的第二商业核心区, 以及东大屿都会的第三个商业核心区;

- 两个策略增长区, 即主要通过填海开拓的东大屿都会, 以及主要通过综合规划及善用棕地和荒置农田拓展的新界北;

-三条发展轴心, 即西部经济走廊、东部知识及科技走 廊, 以及北部经济带。

为配合上述的空间框架, 两个策略增长区将有铁路和公 路支持, 但有关建议仍有待进一步研究。

以上建议的空间框架, 正是呼应了本文前部所述进人 21 世纪的香港城市规划趋向, 利用新界各区的区域优势和运输 基建配套, 构建较均衡的人口与职位空间分布格局, 确立及 加强多中心、多轴线的长远策略规划概念, 使香港迈向一个 可持续、更均衡的空间发展模式。

如所有发展项目完全落实, 建议空间框架提供的最大住 屋容量约为 900 万人。相比基线预测下 2043 年香港人口顶 峰的 822 万人, 上述住屋容量可为人口估算提供 $10 \%$ 的缓冲。 有关缓冲可转化成 “调配空间”, 一方面提升我们的生活质 量（包括改善家居空间及提供更多公共和社区设施）; 另一 方面提高我们在未来变幻莫测形势中的应变能力 (包括预测 的假设有任何改变), 并同时提供调迁空间以应付大规模市 区更新（包括重建）所产生的土地需求。

\section{5 总结}

香港经历了不同年代的规划及实践, 高密度紧凑型的城 市发展模式充分考虑自然环境、经济繁荣、文化保育等因素, 配以合理的空间布局及恰当的公共设施和休喤用地, 以及高 效的市政服务和城市管理, 为市民营造了便捷而又充满活力
的城市环境, 成为现代城市发展模式的一个典范。面对周边 城市的竞争和压力, 香港正积极改善现有的居所和工作地点 不平衡问题, 规划扩展东涌, 发展古洞北及粉岭北、洪水桥 及元朗南等新市镇, 从而提高生产力和生活质量。在高密度 紧凑型城市模式下, 如何不断改善城市的宜居度、正视气候 变化、重视科技发展, 将继续是香港城市规划师最大的挑战, 更是一项没有句号的责任。UP

\section{参考文献}

[1] 何佩然. 城传立新：香港城市规划发展史（1841-2015）[M]. 香港： 中华书局, 2016.

[2] 香港发展局, 香港规划署. 香港 2030+ : 跨越 2030 年的规划远景与策 略规划 [OL/R]. 2017: 17. https://industryhk.org/upload/media/file/4b43 a305135efdb5f84b5a6449567a1c.pdf.

[3] 凌嘉勤. 香港过去和现在的规划及发展经验 [R]. 2016 年香港测量师学 会研讨会, 2016.

[4] 香港发展局. 古洞北粉岭北新发展区, 城市与园景设计 [OL/R]. 2017. http://ktnfln-ndas.gov.hk/tc/2-1-5-about_project.php.

[5]香港规划署, 香港土地工程拓展署. 洪水桥新发展区规划及工程研究, 洪水桥新发展区经修订的建议发展大纲图 [OL/R]. 2016. www.hsknda. gov.hk.

[6] 香港发展局.古洞北 “发展大纲图” [OL/R]. 2017. http://ktnfln-ndas. gov.hk/tc/2-1-3-about_project.php.

[7] 香港发展局, 香港规划署. 规划宜居的高密度城市 [OL/R]. 2016. http://www.hk2030plus.hk/tc/building.asp?form=71.

(本文编辑: 王枫) 